\title{
Sentiment Analysis of Student Engagement with Lecture Recording
}

\author{
Larian M. Nkomo ${ }^{1} \cdot$ Ben K. Daniel ${ }^{1}$ \\ Accepted: 5 November 2020 / Published online: 6 January 2021 \\ (C) Association for Educational Communications \& Technology 2021
}

\begin{abstract}
Lecture recordings are useful learning resources that can support flexible, remote and distance learning, especially during the Covid-19 pandemic. This study explored students' experiences of engaging with recorded lectures and the extent to which such engagement contributes to enhanced learning. The research involved the deployment of a questionnaire to undergraduate and postgraduate students ( $n=660$ ) who had access to lecture recordings at a research intensive public university in New Zealand. Key findings revealed that students who accessed lecture recordings reported an enhanced learning experience. They stated that the availability of lecture recordings created an inclusive learning environment for students with learning disabilities and fostered flexible learning for those who would otherwise be unable to attend lectures either due to sickness or work commitments. Data also suggest that students utilised lecture recordings as supplementary learning resources rather than a substitute for regular lecture attendance. Our findings substantiated previous research studies and additionally demonstrated the various ways in which students engage with lecture recordings. Moreover, the use of sentiment analysis shows how multiple data can be triangulated to confirm or contest research findings. Finally, we believe this study adds to the voice that lecture recordings are vital resources that support students' learning.
\end{abstract}

Keywords Flexible learning $\cdot$ Learning experience $\cdot$ Lecture recordings $\cdot$ Sentiment analysis $\cdot$ Student engagement

\section{Introduction and Related Research}

Understanding the nature of engagement in learning is vital because it affects student achievement (Alrashidi et al. 2016; Kahu 2013; Wyatt 2011). Research has shown that technology plays an essential role in supporting student engagement in learning (Koranteng et al. 2019; Williams and Whiting 2016). More specifically, there is a positive association between students' engagement with technologies such as lecture recording and better learning outcomes (O’Callaghan et al. 2017). Provision of lecture recordings to students supports student learning (Ebbert and Dutke 2020) and helps address competing demands (Chapin 2018; Nordmann and Mcgeorge 2018).

Despite the increasing use of lecture recordings among students, the wide-scale deployment of these resources has received mixed feelings among academics (Edwards and Clinton 2019). Many lecturers doubt the value of lecture recordings in supporting learning, arguing that the use of lecture

Larian M. Nkomo

larian.nkomo@otago.ac.nz

1 University of Otago, Dunedin, New Zealand recording reduces the interaction with students in live lectures and prevents academics from using anecdotes and humour in their teaching (Dona et al. 2017; O'Callaghan et al. 2017; Witthaus and Robinson 2015). Joseph-Richard et al. (2018) reported that some lecturers might object to the use of their recordings because this would be used to monitor teaching performance.

\section{Students Utilisation of Lecture Recordings}

The literature shows a variation in the uptake of recorded lectures; disciplines such as business, the social sciences and the engineering exhibit more positive attitude towards the use of lecture recording compared to lecturers in the science disciplines (Dona et al. 2017; Rahman et al. 2018). Chapin (2018) identified four types of students who engage with lecture recording:

- Students who attended lectures regularly and did not access the lecture recordings;

- Those who regularly attended lectures and used lecture recordings to reinforce what they had learned in class, and for exams; 
- Those who attended lectures and only accessed the recordings when they had missed a lecture, wanted to reinforce what they learned and prepare for exams;

- Those did not attend lectures either by choice or circumstances and relied on the recordings.

Several factors can influence students engagement with lecture recordings, for example, Danielson et al. (2014) reported that students are more likely to view lecture recording in courses delivered in a short period, heavily lecture driven, and containing information not available in other formats. In a recent study, Edwards and Clinton (2019) examined students' engagement with lecture recordings and their impact on learning outcomes. They found that attendance had significantly dropped when lecture recording was made available. However, they noted that students usually engage differently with lecture recordings. This was substantiated by Ebbert and Dutke (2020) who noted that students who use deep learning utilised lecture recordings as supplementary learning materials, and are highly engaged in their learning. Whereas less engaged students who typically adopt surface learning are less likely to use lecture recordings. In contrast, Trenholm et al. (2019) saw that the increase in surface learning is characterised by a combination of a decline in lecture attendance and reliance on recorded lectures. They also identified a negative relationship between student use of lecture recording and academic performance in mathematics.

The concern that lecture recordings are likely to influence lecture attendance is contested (Daniel 2017). MacKay (2019) pointed out that though lecture recording is considered a disruptive technology with the potential to alter class attendance, there is limited evidence that the use of lecture recordings affects student attendance. Other studies also revealed that the availability of lecture recordings does not necessarily lead to a drop in lecture attendance (see Aldamen et al. 2015; Price and Almpanis 2015; Seifert 2019). Seifert (2019) established that the availability of lecture recordings caters for students various learning needs, and these would have little effect on lecture attendance. Students' willingness to attend lectures is partly dependent on the instructor's pedagogical approach, and the design of the course $\left(\mathrm{O}^{\prime}\right.$ Callaghan et al. 2017; Toppin 2011).

When lecture recordings are used as supplementary resources to live lectures, there seems to be a slightly positive correlation between class attendance and recorded videos viewership (Aldamen et al. 2015). The availability of lecture recordings provides students with the following: ability to clarify confusing topics, prepare for exams, learn at their own pace, help them take better notes at their own time and catch up on missed lectures as well as help them balance their schedules between their studies and other obligations (Chapin 2018; Daniel 2017; Dona et al. 2017).
In some instances, students use lecture recording to prepare for lectures. It is also noted that lecturers who use a flipped classroom approach request students to access lecture recordings before planned lectures (Witthaus and Robinson 2015). In general, students view lecture recordings as supplementary learning resources rather than replacing live lectures (Cooke et al. 2012; Copley 2007; Ebbert and Dutke 2020; Leadbeater et al. 2013; Marchand et al. 2014; Nordmann and Mcgeorge 2018; Soong et al. 2006; Traphagan et al. 2010). Lecture recording enables struggling students to view and listen to recordings as many times as they wish. They are also readily available to those students who are unable to attend classes for all sorts of reasons (Joseph-Richard et al. 2018). O'Callaghan et al. (2017) pointed out that the benefits of lecture recordings outweigh the negatives. It is also argued that attending lectures does not automatically translate to learning and that studies have found no relationship between attendance and performance (Eisen et al. 2015; Kauffman et al. 2018). The present study explored how students engage with lecture recordings and the extent to which such engagement enhanced their learning experience. For the purpose of our study, an enhanced learning experience refers to the quality of students' engagement with the content of the course, lecturers, peers and the technology used to mediate the interaction. It does not refer to tangible learning outcomes (e.g. grades) nor the performance of the lecturer per se. The study addresses the following three research questions:

1 What are students' perceptions towards the deployment of lecture recordings?

2 How are students engaging with lecture recording?

3 To what extent does the availability of lecture recording contribute an enhanced student-learning experience?

\section{Methods and Sampling}

The study was guided by a survey research design, utilising an online questionnaire with closed and open-ended questions. We collected quantitative and qualitative data. The qualitative data were used to explain the quantitative measures and to provide context for interpretation of the results.

The recruitment procedure involved profiling university-wide courses $(n=132)$ that provided students with access to recorded lecture materials. After ethical approval, academic staff responsible for each course were requested to send an email inviting students to participate in an online survey to share their experiences about the value of lecture recordings to their learning, and how they engage with these resources. A total of 660 students voluntarily participated in the survey. Table 1 presents the respondents with demographic information. 
Table 1 Respondents demographic information

\begin{tabular}{ll}
\hline Characteristic & Frequency (\%) \\
\hline Age & $576(87)$ \\
$17-24$ & $42(6)$ \\
$25-34$ & $19(3)$ \\
$35-44$ & $13(2)$ \\
$45-54$ & $10(2)$ \\
$55+$ & \\
Year in the programme & $280(43)$ \\
First-year & $164(25)$ \\
Second-year & $116(18)$ \\
Third-year & $54(8)$ \\
Fourth-year & $40(6)$ \\
Postgraduate & \\
Academic division & $308(47)$ \\
Health Sciences & $41(6)$ \\
Commerce & $123(19)$ \\
Humanities & $148(23)$ \\
Sciences & $37(6)$ \\
I do not know & \\
\hline
\end{tabular}

\section{Measures}

We collected students' demographic data and perceptions of the value of recorded lectures to their learning. The questionnaire consisted of a combination of closed-ended questions measured on a Likert scale and open-ended questions. The lecture recording system at the university is set up as an optional tool for lecturers to use in their courses. Students also can interact with lecturers during the lecture, as well as add notes and indicate any items they may find confusing during the lecture.

Since the questionnaire was distributed to students in diverse academic divisions and levels throughout the university, the experiences of the students who responded to the survey varied along with individual skills, and how the lecture capture system was set up. As such, the analysis of the data is mainly focused on self-reported experiences. Cronbach's alpha (a) was used to test for reliability of the questionnaire revealing a value of 0.7 , which is within the acceptable range (Taber 2018).

\section{Data Analysis}

The questionnaire generated quantitative and qualitative data analysed concurrently. The responses to closed-ended questions were analysed using IBM SPSS 22, with descriptive statistics used to summarise the results. Moreover, answers to open-ended questions were compiled and thematically analysed using NVivo software. The process involved reading and re-reading the open-ended responses (Braun and Clarke 2006), themes were then identified within segments of texts associated with the responses to the closed-ended questions. Themes were coded for prevalence as well as the frequency of occurrences.

Conventionally, self-reported measures that can generate a range of rich qualitative and quantitative data are used in education. In the case of qualitative data, data is mostly grouped into themes using subject experiences of the researcher. The process can be daunting and depending on the researcher's experiences might reflect the limited knowledge of the researcher. We utilised Sentiment analysis techniques and algorithms to reduce the daunting tasks of analysing qualitative data in this research.

Although, the application of sentiment analysis approach is limited in educational research, it is essential because identifying students opinions over time enables educators to reflect on their teaching and make necessary changes (Altrabsheh et al. 2013). Therefore, the qualitative data obtained in this study were further analysed using Sentiment analysis, which utilises natural language processing (NLP), text analysis and computational techniques to automate the extraction or classification of sentiment (Hussein 2018).

The algorithms used in sentiment analysis are based on Naive Bayes (NB), Max Entropy (MaxEnt) and Support Vector Machines (SVM) (Altrabsheh et al. 2013; Xie et al. 2019). Sentiment analysis requires, identifying and extracting relevant information about participants' subjective feelings, and experiences towards a product, event or a phenomenon. With an increase in the use of services such as Twitter and online feedback forums, it has become of interest to identify the sentiment of these messages (Kiritchenko et al. 2014; Veletsianos et al. 2018). Sentiment analysis has been used to identify students sentiments in MOOCs towards elements such as peer assessment as well as sentiments that scholars may face online (see Veletsianos et al. 2018; Wen et al. 2014). The sentiment is often rated on a scale between 0 , and 1 with the scores closer to 1 indicating positive sentiment, while scores closer to 0 indicate negative sentiment (Barga et al. 2015). However, sentiments can also be expressed as a range in an n-point scale, e.g., very good, good, satisfactory, bad, very bad (Prabowo and Thelwall 2009).

\section{The Sentiment Analysis Process}

In this study, Microsoft Azure Cognitive Services text analytics API was utilised to conduct the sentiment analysis. It uses a machine-learning classification algorithm to conduct the sentiment analysis. The machine learning approach employed was trained with a large text dataset with records that were labelled for sentiment along 0 and 1 . It then followed the steps of tokenising the input text into individual words and following that up with stemming. 
The features used to train the classifier were then constructed from those words. Some of the elements used in the classifier include N-grams, part-of-speech tagging and word embedding. Once trained, the classifier may then predict the sentiment of any new text (Nagender 2015). N-grams represent all occurrences of $n$ consecutive words in the input text. At the same time, part of speech tagging relates to identifying words that describe a particular part of speech, and word embedding relate to putting words or phrases that are syntactically similar closer together. The process involves performing sentiment analysis on the entire document, rather than extracting sentiment for a particular entity in the text.

To determine the sentiment, the document goes under an objectivity assessment phase, where the model determines whether a document as a whole is objective or contains sentiment. When the document is highly objective, it does not advance to the sentiment detection phase and will result in a .50 score (neutral), with no further processing. For the text that advances, the next phase generates a score above or below .50, depending on the degree of sentiment detected in the document (Hill et al. 2019). A sentiment score $>0.7$ indicates positive sentiment, whereas $<0.4$ indicates negative sentiment, with a sentiment score range between 0.4 and 0.7 indicating neutral sentiment (Chatterjee and Perrizo 2016). The questions that were analysed are found in the Appendix.

\section{Results}

Key findings indicated student's perceptions towards lecture recordings were generally positive and lecture attendance was not overly affected. Overall, students in different years of their programmes stated that access to lecture recordings enhanced their engagement with learning (Fig. 1). Participants also reported increased engagement with content of the course after using lecture recordings. The availability of lecture recordings did not influence engagement with peers and the teacher. Students also mentioned that the use of lecture recordings enhanced their learning experience and that they use these resources to supplement live lectures.

Majority of the cases show that students use lecture recordings to supplement live lectures ( $76 \%$ ), and $42 \%$ indicated that students use lecture recordings as a replacement for missed lectures (see Table 2). Students reported various circumstances (see Table 3) in which they use lecture recording; they use them together with other study-related materials (79\%) and when they are studying at the university $(72 \%)$. The flexibility to the audio while doing other chores, or during leisure time was considered necessary (49\%). Findings from the open-ended responses revealed several themes describing the circumstances in which students are more likely to engage with lecture recordings (see Fig. 2).
Figure 2 indicates that students predominately use lecture recordings when they miss classes due to sickness.

I am quite often sick, and it can be challenging to go to lectures. I will usually watch them all the same day, but I often cannot physically attend, and it is terrific to not have to, on days when it would be a real struggle.

Lecture recordings are invaluable learning tools for students with a learning disability. Students with dyslexia, for example, would find lecture recordings useful as they struggle with taking notes or understanding the writing of their lecturers. One student noted:

.... I am dyslexic, and for some lectures, it is challenging to take note because of the pace of speech or the complexity of the words I am trying to write down or a combination of both. This was the case when I took jurisprudence, and I believe I would have failed the second semester if it were not for lecture recording...

Some forms of disability can significantly disadvantage students from regularly attending lectures, as such lecture recordings provide them with a safety-net.

Due to disability, I am often unable to attend lectures, so being able to view the material at any time is extremely helpful in my studies.

Students with chronic anxiety for all sorts of reasons mentioned that they rely on lecture recordings to succeed in their degree.

This year due to developing of bad anxiety I have engaged with and relied on them far more than I used to and the fact that they are available for me to do that is such a huge help and stress reliever. This has made my experience with podcasts a great one, and I think, in turn, has actually helped my grades somewhat despite what I have been going through.

Lecture recording provides flexible access to learning as many of the students reported that they have family and work commitments that sometimes would not allow them to access live lectures. Some students said that lecture recordings are useful for reviewing lectures. They indicated that when they are assured of access to lecture recordings, they concentrate more on listening to their lecturers instead of listening and taking notes, which impacted on the quality of the notes and amount of information students are likely to miss when multitasking during lectures.

I think it is good to be able just to sit there and absorb all the information in a lecture instead of frantically trying to 
Fig. 1 Overall, to what extent has access to lecture recording improved your learning?

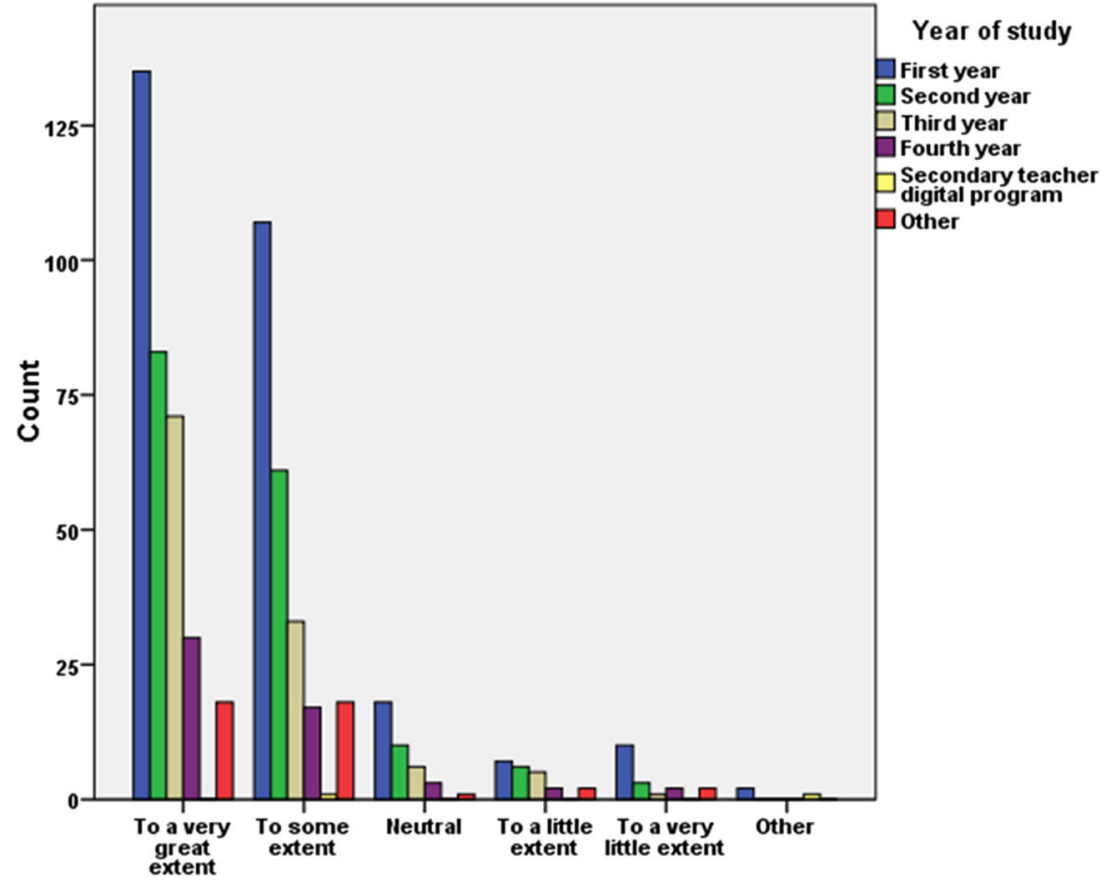

get all the main points down and summarise everything the lecturer says in your head. It makes the lectures a lot more enjoyable, and it is nice to be able to write your notes later when watching the recorded lectures because you can write at your own pace. That being said, I usually do write notes during the lectures anyway.

Students also mentioned that when they face challenges in understanding lecturers, especially those with a different accent than what they are used to, the availability of lecture recording, therefore, provides students with an opportunity to go back and review the lecture.

Being able to hear the lecturer again, especially because with all the different accents, it is good to hear again not in a rush, so I understand better filling in blanks in my notes.
Lecturers speak quickly, and it is impossible to get everything down the first time. I always need to go back and refine my law lecture notes at least three times, so it is vital to be able to review the lecture again.

Over a third of the students, $36.68 \%$ and $20.70 \%$ reported that the availability of the lecture recording is unlikely to affect their physical attendance in lectures. Some said that the availability of recorded lectures was likely to influence their attendance in classes to some extent (16.44\%). $17.66 \%$ of the respondent were neutral with $1.98 \%$ stating something different from the available options (other) (Table 4). The results of the sentiment analysis, however, indicate a mostly negative sentiment of $57 \%$ of the respondents with $40 \%$ being positive and $3 \%$ neutral, reporting over half of the students do not prefer to miss lectures (Table 5). An example of the text and sentiment scores is shown in Table 6.
Table 2 Why do you use lecture recording?

\begin{tabular}{llll}
\hline & \multicolumn{2}{l}{ Responses } & \multirow{2}{*}{ Percent of Cases } \\
\cline { 2 - 3 } & $\mathrm{N}$ & Percent & \\
\hline To supplement live lectures & 477 & $44 \%$ & $76 \%$ \\
As a replacement for missed lectures & 259 & $24 \%$ & $42 \%$ \\
Because I do not clearly understand the lecturer & 189 & $17 \%$ & $30 \%$ \\
Because in general, I find live lectures uninteresting & 31 & $3 \%$ & $5 \%$ \\
Because I often miss lectures & 126 & $11 \%$ & $20 \%$ \\
I do not use recorded materials at all & 7 & $1 \%$ & $1 \%$ \\
Total & 1089 & $100 \%$ & $174 \%$ \\
\hline
\end{tabular}

Dichotomy group tabulated at value 1 (note $\%$ might not add to 100 due to multiple responses). 
Table 3 When students use lecture recording

\begin{tabular}{llll}
\hline & \multicolumn{2}{l}{ Responses } & \multicolumn{2}{l}{$\begin{array}{l}\text { Per cent of } \\
\text { Cases }\end{array}$} \\
\cline { 2 - 3 } & $\mathrm{N}$ & Percent & \\
\hline In my leisure time at home & 316 & $22 \%$ & $49 \%$ \\
During my study time at the university & 465 & $32 \%$ & $72 \%$ \\
While I am doing other things & 63 & $4 \%$ & $10 \%$ \\
In conjunction with other study-related materials (e.g. Notes, textbook) & 510 & $35 \%$ & $79 \%$ \\
In conjunction with other electronic media (not study related to study, e.g. & 89 & $6 \%$ & $14 \%$ \\
$\quad$ Facebook, YouTube, Twitter, etc.) & 1443 & $100 \%$ & $224 \%$ \\
\hline Total & & & \\
\hline
\end{tabular}

${ }^{\text {a }}$ Dichotomy group tabulated at value 1 (note $\%$ might not add to 100 due to multiple responses)
The availability of lecture recordings is not a substitute for lecture attendance. Students generally reported that the availability of lecture recording could not influence their decision to attend classes. They indicated that withholding lecture recordings from all students disadvantage the majority because of few. As one student noted:

I understand that lecturers can be hesitant to allow recorded lectures because they worry students will stop attending in person. I am sure some students don't attend in person because there are recordings. However, if there are no recordings, these students might still miss some classes. Moreover, to force slackers into class, what you do, is punish those students who are genuinely unable to attend in person sometimes.

Some students argue that they should not be disadvantaged since they pay fees to access learning in their terms:

Firstly I believe that since we are the ones paying to have the course taught to us, we should not be disadvantaged

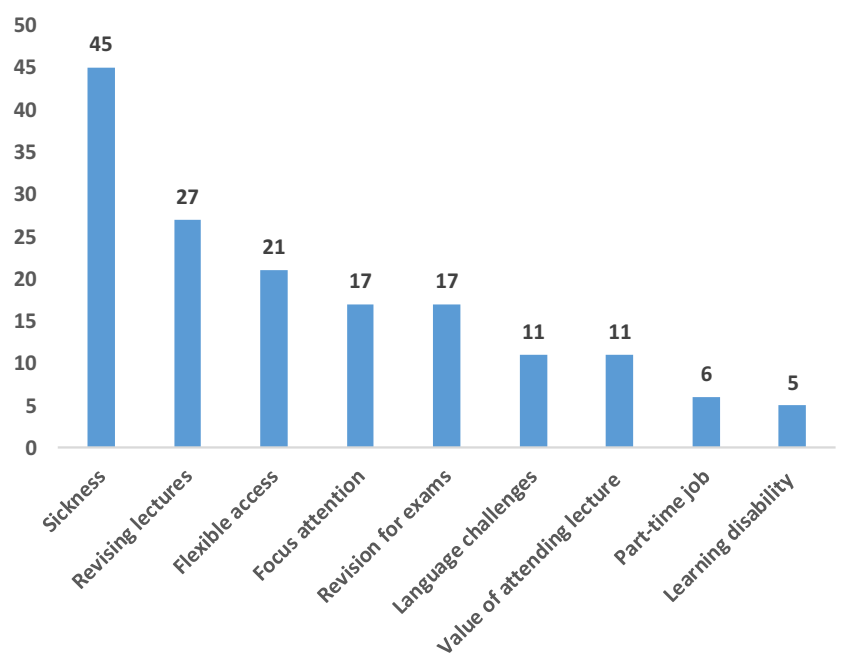

Fig. 2 Reasons why students use recorded lectures because we do not go to class, especially when it is so easy to record a lecture. There are benefits of being in class, which will still encourage people to go. Still, some people, like myself, take far better notes and come away with a far better grasp of the material when done in the context of a study period using a recording. I do not believe it is for the lecturers to force us to go to class to get material effectively, and it advantages students who are very good at taking notes quickly, which many of us are not very good at.

Students also suggested that since they are paying, then it is essential to attend lectures:

Students have a right to be able to access all material (we pay for it) and not being able to make class should not disadvantage a student (insofar as having access to the content is concerned).

Some students reported they use recorded lecture when they do not feel like coming to attend lectures:

I often listen to recorded lectures if I only have one paper that day to save myself coming into a challenging university. Though I plan to change that next year. I also listen to recordings when studying for exams. In which I sit and watch/listen and take notes.
Table 4 Q1. To what extent does having recorded lectures available online make you less likely to attend lectures?

\begin{tabular}{ll}
\hline Response & Frequency (\%) \\
\hline To a little extent & $136(20.70)$ \\
To a very little extent & $241(36.68)$ \\
Neutral & $116(17.66)$ \\
To some extent & $108(16.44)$ \\
To a very great extent & $43(6.54)$ \\
Other & $13(1.98)$ \\
\hline
\end{tabular}


Table 5 Results of sentiment analysis for Q1a Briefly state the reasons for your choice in the question above

\begin{tabular}{ll}
\hline Sentiment & Frequency (\%) \\
\hline Negative & $221(57)$ \\
Neutral & $13(3)$ \\
Positive & $152(39)$ \\
\hline
\end{tabular}

Not all students agree that lectures should all be recorded and made available. Other students reported that lectures should be recorded and only provided to those with prior arrangement, as one student noted:

It is proven that going to lectures is better for study than watching them online. The only reason lectures should be recorded for students who have a prior commitment and cannot make it to the lectures.

We found an association between age and the willingness to attend lectures when lecture recordings are made available (see Table 7). There was significant evidence of an association, $\left(\chi^{2}(20)>=74.3, p=0.001\right)$. A large number of students $(79.64 \%)$ said that the use of lecture recordings enable them to engage with the course content highly. A small number $(12.3 \%)$ indicated they did not know, and $8.1 \%$ indicated their engagement with the course contents did not improve by the use of recorded lectures (Table 8 ). The sentiment analysis results slightly contradict the quantitative data with $56 \%$ of the sentiments negative, 39\% positive and 5\% neutral (Table 9). With regard to student's engagement with lecturers, $29.5 \%$ indicated their engagement with the course lecturer had improved from the use of recorded lectures, $29.5 \%$ indicated they did not know; $41 \%$ reported the use of recorded lectures did not enhance engagement with the course lecturer (Table 8). The sentiment analysis results showed that $56 \%$ of the sentiments were negative, $37 \%$ positive and $7 \%$ neutral (Table 9) supporting the findings of the lecture capture usage not enhancing engagement with the lecturer. Regarding student's engagement with their peers, $10.8 \%$ indicated their engagement with peers had improved from the use of recorded lectures, $28 \%$ indicated they did not know, and $61.2 \%$ reported their engagement with their peers had not been improved (Table 8). The results of the sentiment analysis suggested that students' engagement with peers was not enhanced; $62 \%$ of the sentiments were negative, $31 \%$ positive and $7 \%$ neutral (Table 9). When asked if access to lecture recordings fostered collaboration with peers, $18.94 \%$ indicated it fostered collaboration with their peers. Meanwhile, $27.42 \%$ indicated they did not know, and $53.64 \%$ reported their engagement with their peers had not been improved by the use of recorded lectures (Table 8). The sentiment analysis results revealed that $53 \%$ of the sentiments were negative, $35 \%$ positive and $12 \%$ neutral (Table 9). These results indicate that usage of the recorded lectures did not enhance collaboration among the students. Examples of the text and sentiment scores for each of the above questions are shown as Q2a, Q3a, Q4a and Q5a in Table 10.

When asked whether access to lecture recordings contributed to an enhanced learning experience, most students (87\%) indicated access to recorded lectures improved their learning (Table 11).

\section{Discussion and Conclusion}

The goals of this study were to explore the value of lecture recordings; to understand how students engage with these resources; and the extent to which lecture recordings contribute to an enhanced learning experience. The primary findings suggest that lecture recordings are valuable learning resources; they foster flexible access to learning, and support students who might miss lectures due to illness or work commitments. Our findings are supported by recent research which shows lecture recordings offer students the flexibility to learning (Ebbert and Dutke 2020). Also, the data revealed that when students engage with lecture recordings, they reported an enhanced learning experience.

Further, the availability of lecture recordings support students with special needs (e.g. dyslexia). This supports the view that lecture recordings can facilitate equitable access to learning materials (Chang 2007) but also students with work and family commitments (Hall and Ivaldi 2017; Taplin et al. 2014). It is critical to note that students do not necessarily exhibit the same usage patterns of lecture recordings (O'Callaghan et al. 2017; Witthaus and Robinson 2015). Data showed revealed students use lecture recordings mainly as supplementary learning resources, other use them to support revision for exams, to help them in making notes, and others use them as a replacement for missed lectures.

Key findings showed that students use lecture recordings as a supplementary resource to support revisions for preparing
Table 6 Q1a Briefly state the reasons for your choice in the question above

\begin{tabular}{lll}
\hline Text & Score & Sentiment \\
\hline $\begin{array}{l}\text { I only miss lectures when I am sick or unable to attend due to transportation issues. } \\
\text { It is a definite factor in my decision making - I recognise the added benefit of the live } \\
\begin{array}{l}\text { lecture. Still, the availability of an alternative option can be a strong influencing factor. } \\
\text { I }<3 \text { class }\end{array}\end{array}$ & 0.00 & Negative \\
\hline
\end{tabular}


Table 7 To what extent does having recorded lectures available online; make you less likely to attend lectures? (Based on Age)

\begin{tabular}{lllllll}
\hline & \multicolumn{2}{l}{ Age } & & & & Total \\
\cline { 2 - 5 } & $17-24$ & $25-34$ & $35-44$ & $45-54$ & $55+$ & \\
\hline To a little extent & $129(96 \%)$ & $3(2 \%)$ & $2(2 \%)$ & $0(0 \%)$ & $1(1 \%)$ & $135(100 \%)$ \\
To a very little extent & $207(86 \%)$ & $13(5 \%)$ & $8(3 \%)$ & $8(3 \%)$ & $4(2 \%)$ & $240(100 \%)$ \\
Neutral & $100(86 \%)$ & $13(11 \%)$ & $2(2 \%)$ & $0(0 \%)$ & $1(1 \%)$ & $116(100 \%)$ \\
To a very great extent & $34(79 \%)$ & $5(12 \%)$ & $1(2 \%)$ & $1(2 \%)$ & $2(5 \%)$ & $43(100 \%)$ \\
To some extent & $99(93 \%)$ & $4(4 \%)$ & $3(3 \%)$ & $1(1 \%)$ & $0(0 \%)$ & $107(100 \%)$ \\
Other & $5(36 \%)$ & $3(21 \%)$ & $2(14 \%)$ & $3(21 \%)$ & $1(7 \%)$ & $14(100 \%)$ \\
& $574(88 \%)$ & $41(6 \%)$ & $18(3 \%)$ & $13(2 \%)$ & $9(1 \%)$ & $655(100 \%)$ \\
\hline
\end{tabular}

study notes or for exams. This observation is similar to research that suggests students typically consider lectures as learning events that provide an overview of core learning activities, and other learning materials as opportunities for consolidating information acquired through lectures (Dommett et al. 2019). Even though the provision of lecture recordings influence attendance, students occasionally miss lectures due to circumstances beyond their control (Wammes et al. 2019). Therefore, there is inadequate evidence to suggest that the availability of lecture recording alone can lead to a decline in lecture attendance (Nordmann and Mcgeorge (2018).

The survey also revealed that students who used lecture recordings reported improved engagement with the content of the course. They said that the availability of the recorded lectures served as a safety-net, whereby they paid more attention in lectures, instead of taking notes and listening to the lecturer at the same time. However, some students in the survey reported that access to lecture recordings did not improve their engagement with their lecturers; the results of the sentiment analysis corroborated these findings. We suspected that students reported less engagement with the lecturer because the lectures were simply recorded and presented to students, without any preplanned learning redesign or the provision of instructional scaffolding to students after they engage with lecture recordings. This is the case when lecture recordings are used as part of the flipped classroom experience. The sentiment analysis also showed that the use of lecture recordings did not improve student's collaboration and engagement with peers.

\section{Recommendations and Implications}

Some lecturers have linked the declining lecture attendance to the provisions of lecture recordings ahead of scheduled lectures. However, in this study, students reported that lecture recordings are valuable learning resources; when combined with regular lecture attendance to enhance learning. It is, therefore, critical that research focus on identifying learning strategies that support better use of lecture recordings, with an ultimate goal of engaging, enhancing and empowering students learning. Providing these resources to students before lectures can help students prepare for lectures, at the same time teachers can use more of the class time to foster interaction and active learning.

During the Covid-19 period, lecture recordings are more critical because they can support flexible access to learning. Also, the availability of recordings ahead of scheduled lectures can enable students to prepare for lectures and engage better in-
Table 8 Student engagement outcomes

\begin{tabular}{|c|c|c|c|c|}
\hline Option & No & $\begin{array}{l}\text { Don't } \\
\text { Know }\end{array}$ & Yes & Total \\
\hline $\begin{array}{l}\text { Do you think the use of recorded lectures has improved your } \\
\text { engagement with the content of the paper }\end{array}$ & $\begin{array}{l}53 \\
(8.1- \\
\%)\end{array}$ & $\begin{array}{l}81 \\
\quad(12.3- \\
\quad \%)\end{array}$ & $\begin{array}{l}524 \\
\quad(79.6- \\
\%)\end{array}$ & $\begin{array}{l}658 \\
(10- \\
0 \%)\end{array}$ \\
\hline $\begin{array}{l}\text { Do you think the use of recorded lectures has improved your } \\
\text { engagement with the lecturer }\end{array}$ & $\begin{array}{l}268 \\
\quad(41.0- \\
\quad \%)\end{array}$ & $\begin{array}{l}193 \\
(29.5- \\
\%)\end{array}$ & $\begin{array}{l}193 \\
(29.5- \\
\%)\end{array}$ & $\begin{array}{l}654 \\
(10- \\
0 \%)\end{array}$ \\
\hline $\begin{array}{l}\text { Do you think the use of recorded lectures has improved your } \\
\text { engagement with peers }\end{array}$ & $\begin{array}{l}403 \\
\quad(61.2- \\
\%)\end{array}$ & $\begin{array}{l}184 \\
\quad(28.0- \\
\%)\end{array}$ & $71(10.8 \%)$ & $\begin{array}{l}658 \\
(10- \\
0 \%)\end{array}$ \\
\hline $\begin{array}{l}\text { Do you think the use of recorded lectures has led to } \\
\text { collaboration with peers }\end{array}$ & $\begin{array}{l}354 \\
\quad(53.6- \\
4 \%)\end{array}$ & $\begin{array}{l}181 \\
\quad(27.4- \\
2 \%)\end{array}$ & $\begin{array}{l}125 \\
(18.94- \\
\%)\end{array}$ & $\begin{array}{l}660 \\
(10- \\
0 \%)\end{array}$ \\
\hline
\end{tabular}


Table 9 Sentiment analysis of students' lecture recordings engagement outcomes

\begin{tabular}{llll}
\hline & $\begin{array}{l}\text { Negative } \\
\text { Frequency } \\
(\%)\end{array}$ & $\begin{array}{l}\text { Neutral } \\
\text { Frequency } \\
(\%)\end{array}$ & $\begin{array}{l}\text { Positive } \\
\text { Frequency } \\
(\%)\end{array}$ \\
\hline $\begin{array}{l}\text { Do you think the use of recorded lectures has improved your } \\
\text { engagement with the content of the paper? }\end{array}$ & $161(56)$ & $13(5)$ & $112(39)$ \\
$\begin{array}{l}\text { Do you think the use of recorded lectures has improved your } \\
\text { engagement with the lecturer? }\end{array}$ & $125(56)$ & $16(7)$ & $84(37)$ \\
$\begin{array}{l}\text { Do you think the use of recorded lectures has improved your } \\
\text { engagement with peers? }\end{array}$ & $133(62)$ & $15(7)$ & $68(31)$ \\
$\begin{array}{l}\text { Do you think the use of recorded lectures has led to collaboration } \\
\text { with peers? }\end{array}$ & $98(53)$ & $23(12)$ & $64(35)$ \\
\hline
\end{tabular}

class discussion. Further, when used strategically, lecture recordings can afford lecturers with more time during lectures, for clarifying difficult concepts, supporting and scaffolding student learning, rather than repeating lecture content. Moreover, institutional policies can provide frameworks and guidelines, to further allay educators' concerns relating to privacy, intellectual property rights and informed consent in lecture recording. With different types of data available to researchers, our use of sentiment analysis illustrates how qualitative data can be triangulated to confirm or contest research findings.

Overall, findings in the survey suggest that students viewed lecture recordings as supplementary learning resources rather than a substitute for regular lecture attendance. These findings substantiated previous research studies and additionally demonstrated the various ways in which students are likely to engage with lecture recordings. Moreover, the use of sentiment analysis showed how multiple data could be triangulated to confirm or contest research findings.

\section{Limitations and Future Work}

One of the drawbacks of questionnaires used as self-reported measures is the inability to control the response rate and the possibility of missing data. Due to this, some of the questions had missing data or less respondents. We used sentiment analysis to corroborate the results of the self-reported data from the questionnaire. However, sentiment analysis limits the ability to pre-train the dataset and depends on the pre-trained classifier, and the results may not accurately score the sentiments. Also, most of the sentiment analysis algorithms do not consider the context of the text. The classifier used in this study is only accurate with shorter sentences then large blocks of text (Hill et al. 2019). However, this tool outperforms other services such as the Stanford NLP Sentiment Analysis engine on short as well as longer blocks of text (Chatterjee and Perrizo 2016). Furthermore, because the questionnaire was distributed to students in diverse academic divisions and levels
Table 10 Examples of text and sentiment scores

\begin{tabular}{|c|c|c|c|}
\hline Question & Text & Score & Sentiment \\
\hline \multirow[t]{3}{*}{ Q2a } & Hard to say because I have always been useless when it comes to studying & 0.01 & Negative \\
\hline & N/A & 0.5 & Neutral \\
\hline & Improved understanding & 0.99 & Positive \\
\hline \multirow[t]{3}{*}{ Q3a } & $\begin{array}{l}\text { unfortunately, with recorded lectures, there is less engagement due to less } \\
\text { questions to ask }\end{array}$ & 0.03 & Negative \\
\hline & Do not see the lecturer from podcasts & 0.5 & Neutral \\
\hline & $\begin{array}{l}\text { In lectures, you have the opportunity to ask impromptu questions and listen } \\
\text { to other students' questions and subsequent answers. This is also a } \\
\text { valuable way to learn }\end{array}$ & 0.95 & Positive \\
\hline \multirow[t]{3}{*}{ Q4a } & I watch them alone & 0.01 & Negative \\
\hline & $\begin{array}{l}\text { Isn't the point of going to a lecture to engage with the lecturer and the } \\
\text { material they are presenting rather than with your peers }\end{array}$ & 0.5 & Neutral \\
\hline & $\begin{array}{l}\text { Makes tutorials easier as I have detailed notes that I can use for and help with } \\
\text { discussions }\end{array}$ & 0.96 & Positive \\
\hline \multirow[t]{3}{*}{ Q5a } & $\begin{array}{l}\text { It allows everyone to re-watch things together if they so wish, but I do not do } \\
\text { that, so I do not know }\end{array}$ & 0.04 & Negative \\
\hline & $\begin{array}{l}\text { Looking at the lectures again, taking time away from outside of class for } \\
\text { interacting with others }\end{array}$ & 0.5 & Neutral \\
\hline & Helpful for the asking/explaining concepts & 0.98 & Positive \\
\hline
\end{tabular}


Table 11 Q6 Overall, to what extent has access to recorded lectures improved your learning?

\begin{tabular}{ll}
\hline Response & Frequency (\%) \\
\hline To a little extent & $22(3)$ \\
To a very little extent & $18(3)$ \\
Neutral & $39(6)$ \\
To some extent & $238(36)$ \\
To a very great extent & $339(51)$ \\
Other & $4(1)$ \\
\hline
\end{tabular}

throughout the university, the study did not capture the design of the videos, as well as the duration of the videos, as these may have varied.

In the future, we will obtain data from the lecture recording system and making additional analysis against what students reported about the value of lecture recordings and the learning analytics obtained from the system. It would also be imperative to specifically explore how undergraduate students engaged with lecture recordings compared to postgraduate students. We suspected that lecturer recordings are used differently by different students. Understanding how individuals and group used these resources can provide insights into how to individualise learning support.

Acknowledgements We acknowledge funding from the University of Otago Doctoral Scholarship funds and Performance-Based Research Funding (PBRF).

Data Availability The datasets generated during and/or analysed during the current study are available from the corresponding author on reasonable request.

\section{Compliance with Ethical Standards}

Conflict of Interest The authors have no competing interests to declare.

Research Involving Human Participants and/ or Animals The study has been approved by the institution's research ethics committee and has been conducted in accordance with ethical standards.

Informed Consent Informed consent was obtained from all participants included in the study through voluntary participation.

\section{Appendix}

Table 12 Summary of Questions used in the study

\begin{tabular}{|c|c|c|c|c|}
\hline Code & Question & Responses & Total responses & Analysis Type \\
\hline Q1 & $\begin{array}{l}\text { To what extent does having recorded } \\
\text { lectures available online makes you } \\
\text { less likely to attend lectures? }\end{array}$ & $\begin{array}{l}\text { To a very great extent } \\
\text { To some extent } \\
\text { Neutral } \\
\text { To a little extent } \\
\text { To a very little extent } \\
\text { Other: }\end{array}$ & 657 & Descriptive statistics \\
\hline Q1a & $\begin{array}{l}\text { Briefly state the reasons for your choice } \\
\text { in the question above. }\end{array}$ & Open ended & 386 & Sentiment analysis \\
\hline Q2 & $\begin{array}{l}\text { Do you think the use of recorded } \\
\text { lectures has improved your } \\
\text { engagement with the content of the } \\
\text { course? }\end{array}$ & $\begin{array}{l}\text { Yes } \\
\text { No } \\
- \\
\text { Don't Know }\end{array}$ & 658 & Descriptive statistics \\
\hline Q2a & $\begin{array}{l}\text { Briefly state the reasons for your choice } \\
\text { in the question above. }\end{array}$ & Open ended & 286 & Sentiment analysis \\
\hline Q3 & $\begin{array}{l}\text { Do you think the use of recorded } \\
\text { lectures has improved your } \\
\text { engagement with the lecturer? }\end{array}$ & $\begin{array}{l}\text { Yes } \\
\text { No } \\
\text { Don't Know }\end{array}$ & 654 & Descriptive statistics \\
\hline Q3a & $\begin{array}{l}\text { Briefly state the reasons for your choice } \\
\text { in the question above. }\end{array}$ & Open ended & 225 & Sentiment analysis \\
\hline Q4 & $\begin{array}{l}\text { Do you think the use of recorded } \\
\text { lectures has improved your } \\
\text { engagement with peers? }\end{array}$ & $\begin{array}{l}\text { Yes } \\
\text { No } \\
- \\
\text { Don't Know }\end{array}$ & 658 & Descriptive statistics \\
\hline Q4a & $\begin{array}{l}\text { Briefly state the reasons for your } \\
\text { choice in the question above. }\end{array}$ & Open ended & 216 & Sentiment analysis \\
\hline Q5 & $\begin{array}{l}\text { Do you think the use of recorded } \\
\text { lectures has led to collaboration } \\
\text { with peers? }\end{array}$ & $\begin{array}{l}\text { Yes } \\
\text { No }\end{array}$ & 660 & Descriptive statistics \\
\hline
\end{tabular}


Table 12 (continued)

\begin{tabular}{|c|c|c|c|c|}
\hline Code & Question & Responses & Total responses & Analysis Type \\
\hline & & Don't Know & & \\
\hline Q5a & $\begin{array}{l}\text { Briefly state the reasons for your } \\
\text { choice in the question above. }\end{array}$ & Open ended & 185 & Sentiment analysis \\
\hline \multirow[t]{5}{*}{ Q6 } & \multirow{5}{*}{$\begin{array}{l}\text { Overall, to what extent has access to } \\
\text { recorded lectures improved your } \\
\text { learning? }\end{array}$} & $\begin{array}{l}\text { To a very great extent } \\
\text { To some extent }\end{array}$ & \multirow[t]{5}{*}{660} & \multirow[t]{5}{*}{ Descriptive statistics } \\
\hline & & Neutral & & \\
\hline & & To a little extent & & \\
\hline & & To a very little extent & & \\
\hline & & Other: & & \\
\hline \multirow[t]{5}{*}{ Q7 } & \multirow[t]{5}{*}{ I use recorded lecture materials } & $\begin{array}{l}\text { In my leisure time at home } \\
\text { During my study time at the university }\end{array}$ & \multirow[t]{5}{*}{657} & \multirow[t]{5}{*}{ Descriptive statistics } \\
\hline & & While I am doing other things & & \\
\hline & & $\begin{array}{l}\text { In conjunction with other study-related ma- } \\
\text { terials (e.g. Notes, textbook) }\end{array}$ & & \\
\hline & & $\begin{array}{l}\text { In conjunction with other electronic media } \\
\text { (not study related to study, e.g. Facebook, } \\
\text { YouTube, Twitter, etc.) }\end{array}$ & & \\
\hline & & Other: & & \\
\hline
\end{tabular}

\section{References}

Aldamen, H., Al-Esmail, R., \& Hollindale, J. (2015). Does lecture capturing impact student performance and attendance in an introductory accounting course? Accounting Education, 24(4), 291-317. https:// doi.org/10.1080/09639284.2015.1043563.

Alrashidi, O., Phan, H. P., \& Ngu, B. H. (2016). Academic engagement: An overview of its definitions, dimensions, and major Conceptualisations. International Education Studies, 9(12), 41-52. https://doi.org/10.5539/ies.v9n12p41.

Altrabsheh, N., Gaber, M. M., \& Cocea, M. (2013). SA-E: Sentiment analysis for education. Paper presented at the International Conference on Intelligent Decision Technologies.

Barga, R., Fontama, V., Tok, W. H., \& Cabrera-Cordon, L. (2015). Predictive analytics with Microsoft Azure machine learning: Springer.

Braun, V., \& Clarke, V. (2006). Using thematic analysis in psychology. Qualitative Research in Psychology, 3(2), 77-101. https://doi.org/ 10.1191/1478088706qp063oa.

Chang, S. (2007). Academic perceptions of the use of Lectopia: A University of Melbourne example. Paper presented at the ICT: Providing choices for learners and learning. Proceedings ascilite Singapore 2007.

Chapin, L. A. (2018). Australian university students' access to web-based lecture recordings and the relationship with lecture attendance and academic performance. Australasian Journal of Educational Technology, 34(5), 1-12. https://doi.org/10.14742/ajet.2989.

Chatterjee, A., \& Perrizo, W. (2016). Investor classification and sentiment analysis. Paper presented at the 2016 IEEE/ACM International Conference on Advances in Social Networks Analysis and Mining (ASONAM).

Cooke, M., Watson, B., Blacklock, E., Mansah, M., Howard, M., Johnston, A., et al. (2012). Lecture capture: First year student nurses' experiences of a web based lecture technology. The Australian Journal of Advanced Nursing, 29(3), 14.

Copley, J. (2007). Audio and video podcasts of lectures for campus-based students: Production and evaluation of student use. Innovations in
Education and Teaching International, 44(4), 387-399. https://doi. org/10.1080/14703290701602805.

Daniel, B. K. (2017). Enterprise lecture capture technologies and value to student learning. International Journal of Information and Communication Technologies in Education, 6(2), 23-36. https:// doi.org/10.1515/ijicte-2017-0009.

Danielson, J., Preast, V., Bender, H., \& Hassall, L. (2014). Is the effectiveness of lecture capture related to teaching approach or content type? Computers \& Education, 72, 121-131. https://doi.org/10. 1016/j.compedu.2013.10.016.

Dommett, E. J., van Tilburg, W., \& Gardner, B. (2019). A case study: Views on the practice of opting in and out of lecture capture. Education and Information Technologies. https://doi.org/10.1007/ s10639-019-09918-y.

Dona, K. L., Gregory, J., \& Pechenkina, E. (2017). Lecture-recording technology in higher education: Exploring lecturer and student views across the disciplines. Australasian Journal of Educational Technology, 33(4). https://doi.org/10.14742/ajet.3068.

Ebbert, D., \& Dutke, S. (2020). Patterns in students' usage of lecture recordings: A cluster analysis of self-report data. Research in Learning Technology, 28. https://doi.org/10.25304/rlt.v28.2258.

Edwards, M. R., \& Clinton, M. E. (2019). A study exploring the impact of lecture capture availability and lecture capture usage on student attendance and attainment. Higher Education, 77(3), 403-421. https://doi.org/10.1007/s10734-018-0275-9.

Eisen, D. B., Schupp, C. W., Isseroff, R. R., Ibrahimi, O. A., Ledo, L., \& Armstrong, A. W. (2015). Does class attendance matter? Results from a second-year medical school dermatology cohort study. International Journal of Dermatology, 54(7), 807-816. https://doi. org/10.1111/ijd.12816.

Hall, G., \& Ivaldi, A. (2017). A qualitative approach to understanding the role of lecture capture in student learning experiences. Technology, Pedagogy and Education, 26(4), 383-394. https://doi.org/10.1080/ 1475939X.2016.1263805.

Hill, A., Erickson, D., Sharkey, K., Ericson, G., Wells, J., Steen, H., . . . Farley, P. (2019). Sentiment analysis using the Text Analytics from Azure Cognitive Services | Microsoft Docs. Retrieved April 25, 
2019, from https://docs.microsoft.com/en-us/azure/cognitiveservices/text-analytics/how-tos/text-analytics-how-to-sentimentanalysis

Hussein, D. M. E.-D. M. (2018). A survey on sentiment analysis challenges. Journal of King Saud University - Engineering Sciences, 30(4), 330-338. https://doi.org/10.1016/j.jksues.2016.04.002.

Joseph-Richard, P., Jessop, T., Okafor, G., Almpanis, T., \& Price, D. (2018). Big brother or harbinger of best practice: Can lecture capture actually improve teaching? British Educational Research Journal, 44(3), 377-392. https://doi.org/10.1002/berj.3336.

Kahu, E. R. (2013). Framing student engagement in higher education. Studies in Higher Education, 38(5), 758-773. https://doi.org/10. 1080/03075079.2011.598505.

Kauffman, C. A., Derazin, M., Asmar, A., \& Kibble, J. D. (2018). Relationship between classroom attendance and examination performance in a second-year medical pathophysiology class. Advances in Physiology Education, 42(4), 593-598. https://doi.org/10.1152/ advan.00123.2018.

Kiritchenko, S., Zhu, X., \& Mohammad, S. M. (2014). Sentiment analysis of short informal texts. Journal of Artificial Intelligence Research, 50, 723-762. https://doi.org/10.1613/jair.4272.

Koranteng, F. N., Wiafe, I., \& Kuada, E. (2019). An empirical study of the relationship between social networking sites and students' engagement in higher education. Journal of Educational Computing Research, 57(5), 1131-1159. https://doi.org/10.1177/ 0735633118787528 .

Leadbeater, W., Shuttleworth, T., Couperthwaite, J., \& Nightingale, K. P. (2013). Evaluating the use and impact of lecture recording in undergraduates: Evidence for distinct approaches by different groups of students. Computers \& Education, 61, 185-192. https://doi.org/10. 1016/j.compedu.2012.09.011.

MacKay, J. R. (2019). Show and 'tool': How lecture recording transforms staff and student perspectives on lectures in higher education. Computers \& Education. https://doi.org/10.1016/j.compedu.2019. 05.019 .

Marchand, J.-P., Pearson, M. L., \& Albon, S. P. (2014). Student and faculty member perspectives on lecture capture in pharmacy education. American Journal of Pharmaceutical Education, 78(4), 74. https://doi.org/10.5688/ajpe78474.

Nagender, P. (2015). Introducing Text Analytics in the Azure ML Marketplace. Retrieved April 25, 2019, from https://blogs.technet. microsoft.com/machinelearning/2015/04/08/introducing-textanalytics-in-the-azure-ml-marketplace/

Nordmann, E., \& Mcgeorge, P. (2018). Lecture capture in higher education: Time to learn from the learners. PsyArXiv. https://doi.org/10. 31234/osf.io/ux29v.

O’Callaghan, F. V., Neumann, D. L., Jones, L., \& Creed, P. A. (2017). The use of lecture recordings in higher education: A review of institutional, student, and lecturer issues. Education and Information Technologies, 22(1), 399-415. https://doi.org/10.1007/s10639-0159451-z.

Prabowo, R., \& Thelwall, M. (2009). Sentiment analysis: A combined approach. Journal of Informetrics, 3(2), 143-157. https://doi.org/10. 1016/j.joi.2009.01.003.

Price, D., \& Almpanis, T. (2015). Student and staff perceptions in the impact of lecture capture. Paper presented at the the international conference on information communication Technologies in Education 2015. ICICTE.

Rahman, A., Shah, M. A. R., \& Chowdhury, S. H. (2018). Lecture capture use in engineering education: Influence of students' social and behavioral factors and teachers' perceptions. Computer Applications in Engineering Education, 26(3), 500-508. https://doi.org/10.1002/ cae. 21902 .

Seifert, T. (2019). Two pedagogical models of video integration in multiparticipant courses. Journal of Educators Online, 16(1), n1. https://doi.org/10.9743/jeo.2019.16.1.12.

Soong, S. K. A., Chan, L. K., Cheers, C., \& Hu, C. (2006). Impact of video recorded lectures among students. Paper presented at the 23rd annual ascilite conference: Who's learning? Whose technology?

Taber, K. S. (2018). The use of Cronbach's alpha when developing and reporting research instruments in science education. Research in Science Education, 48(6), 1273-1296.

Taplin, R. H., Kerr, R., \& Brown, A. M. (2014). Opportunity costs associated with the provision of student services: A case study of webbased lecture technology. Higher Education, 68(1), 15-28. https:// doi.org/10.1007/s10734-013-9677-x.

Toppin, I. N. (2011). Video lecture capture (VLC) system: A comparison of student versus faculty perceptions. Education and Information Technologies, 16(4), 383-393. https://doi.org/10.1007/s10639010-9140-x.

Traphagan, T., Kucsera, J. V., \& Kishi, K. (2010). Impact of class lecture webcasting on attendance and learning. Educational Technology Research and Development, 58(1), 19-37. https://doi.org/10.1007/ s11423-009-9128-7.

Trenholm, S., Hajek, B., Robinson, C. L., Chinnappan, M., Albrecht, A., \& Ashman, H. (2019). Investigating undergraduate mathematics learners' cognitive engagement with recorded lecture videos. International Journal of Mathematical Education in Science and Technology, 50(1), 3-24. https://doi.org/10.1080/0020739X.2018. 1458339.

Veletsianos, G., Kimmons, R., Larsen, R., Dousay, T. A., \& Lowenthal, P. R. (2018). Public comment sentiment on educational videos: Understanding the effects of presenter gender, video format, threading, and moderation on YouTube TED talk comments. PLoS One, 13(6), e0197331. https://doi.org/10.1371/journal.pone. 0197331.

Wammes, J. D., Ralph, B. C. W., Mills, C., Bosch, N., Duncan, T. L., \& Smilek, D. (2019). Disengagement during lectures: Media multitasking and mind wandering in university classrooms. Computers \& Education, 132, 76-89. https://doi.org/10.1016/j.compedu.2018. 12.007 .

Wen, M., Yang, D., \& Rose, C. (2014). Sentiment Analysis in MOOC Discussion Forums: What does it tell us? Paper presented at the Educational data mining 2014.

Williams, D., \& Whiting, A. (2016). Exploring the relationship between student engagement, twitter, and a learning management system: A study of undergraduate marketing students. International Journal of Teaching and Learning in Higher Education, 28(3), 302-313.

Witthaus, G. R., \& Robinson, C. L. (2015). Lecture capture literature review: A review of the literature from 2012-2015. Loughborough: Centre for Academic Practice, Loughborough University.

Wyatt, L. G. (2011). Nontraditional student engagement: Increasing adult student success and retention. The Journal of Continuing Higher Education, 59(1), 10-20. https://doi.org/10.1080/07377363.2011. 544977.

Xie, X., Ge, S., Hu, F., Xie, M., \& Jiang, N. (2019). An improved algorithm for sentiment analysis based on maximum entropy. Soft Computing, 23(2), 599-611. https://doi.org/10.1007/s00500-0172904-0.

Publisher's Note Springer Nature remains neutral with regard to jurisdictional claims in published maps and institutional affiliations. 